zurückzusenden, sondern auch Ihre Wünsche und Anregungen direkt an mich zu übersenden. Die Adresse ist jedem Heft der Zeitschrift Grundwasser unter der Rubrik „FH-DGG in eigener Sache" zu entnehmen.

Ich freue mich auf einen regen Meinungsaustausch!

Jörg Reichling, Hannover

\section{International Association of Hydrogeologists (IAH)}

\section{Sektion Deutschland}

IAH-Mitglieder erhielten im Dezember 1996 eine Sendung bestehend aus: $\mathrm{Hy}$ drogeology Journal Vol. 4, No. 4, 1996, News \& Information C 12, Nov. 1996, Membership Directory 1997 und 1. Zirkular einer Konferenz „Groundwater: Sustainable Solutions" im Februar 1998 in Melbourne.

$\mathrm{Zu}$ dieser Sendung nachfolgende Erläuterungen.

Das jüngste Heft des Hydrogeology Journal (HJ) enthält nicht nur sechs interessante Artikel (vier „Papers“, zwei „Reports“), sondern auch einen 22-seitigen Index (1991-96), alphabetisch geordnet nach: Autoren, Titeln und Themen. Bei letzteren finden sich unter "Germany" ganze zwei Beiträge. Hierin sehe ich (als Associate Editor) wiederum Anlaß, Landsleute aufzurufen, dem HJ Beiträge einzureichen. Der wissenschaftliche Editor, Cliff I. Voss vom U.S. Geological Survey, teilt mit, daß HJ ab 1997 neu formatiert wird und dadurch pro Heft ca. $20 \%$ mehr Text aufgenommen werden kann. Für 1997 sind zwei HJ-Sonderhefte vorgesehen: Nr. 1 über Probleme der Grundwasserversalzung (Editor: Dr. G. Jacobsen, Australien) und Nr. 4 zu Ehren von Prof. Gene Simpson, dem HJ-Gründer (Editor: Prof. S. Neumann und M. Campana). Über weitere Absichten des $\mathrm{HJ}$ wird später berichtet. Rund 100 Artikel sind derzeit in Bearbeitung. Bisher wurden ca. 140 Beiträge von mehr als 200 Autoren aus etwa 40 Ländern publiziert. News \& Information C 12 informieren u. a. über die IAH-Generalversammlung am 07. August 1996 in Peking im Rahmen des 30. Internationalen Geologenkongresses, über die Ergebnisse der Wahlen zum Council und über die teilweise Er-höhung der Mitgliedsbeiträge und enthalten einen Nachruf auf Stevenson Buchan, Gründungsmitglied, zeitweise Präsident und Ehrenmitglied der IAH. Neu gewählter Präsident ist Prof. Michael Knight, Australien, die „President's Award“ für 1996 erhielt Prof. Yuan Daoxin, China. Beide Persönlichkeiten sind Teilnehmern an IAHKongressen, etwa Guilin 1988 und Adelaide 1994, bestens bekannt. Präsident Knight stellt sich in einer engagierten, zukunftsweisenden Rede vor; er stützt sich weiterhin auf Generalsekretär A. Skinner, UK, und Schatzmeister W. Struckmeier. Unvermeidlich war offenbar die Erhöhung bzw. Anpassung der Mitgliedsbeiträge, die seit Jahren unverändert waren. Einstimmiger Beschluß der Generalversammlung ist: Ab 01. Januar 1997 zahlen persönliche Mitglieder in "high income countries" DM 82,- pro Jahr, in ,low in-come countries" und Studierende (zwei Jahre lang) unverändert DM 40,-. Korporierte Mitglieder zahlen DM 164,-/Jahr (Institute o. ä.) bzw. DM 410,-/Jahr (kommerziell orientierte Unternehmen). Verf. hat früher wiederholt auf die Vorteile einer IAHMitgliedschaft hingewiesen.

Das neue Mitgliederverzeichnis enthält Namen und Anschriften von Vorstand, Kommissionen/Arbeitsgruppen, Nationalkomitees (31), eine Kurzfassung der Historie der IAH, Publikationen, Informationen über Mitgliedschaft, einige korporierte Mitglieder (darunter ein deutsches) und nicht zuletzt die Auflistung der mehr als 3000 Mitglieder geordnet nach Ländern. Bei den knapp 200 deutschen Mitgliedern haben sich bezüglich deren Namen bzw. Anschriften einige Fehler eingeschlichen, die auszumerzen wir $z$. Z. bemüht sind. Die Tagung in Melbourne (08. bis 13. Februar 1998) liegt zwischen dem 27. (Nottingham) und 28. IAH-Kongreß (Las Vegas). Das Thema ist allgemein gehalten, allerdings mit spezifischen Problemen in Australien (Staat Victoria), u. a. Versalzung, Kontamination, Grund-/ Oberflächenwasser-Interaktion und urbane Hydrologie. Mancher mag die Gelegenheit nutzen wollen, ein faszinierendes Land mit seinen komplexen hydrogeologischen Gegebenheiten kennenzulernen.
Schließlich - aus gegebenem Anlaß jüngste Informationen über den 27. IAHKongreß vom 21. bis 27. September 1997 in Nottingham (Generalthema: „Groundwater in the Urban Environment"). Einer der Chairmen, Prof. Stephen Foster, schildert ausführlich Probleme der Kongreßvorbereitung, vor allem des wissenschaftlichen Programms. Bis Mitte 1996 war das Abstract-Angebot bescheiden, um dann bis Ende September 96 auf 300 aus 59 Ländern zu explodieren. Die technischen Gegebenheiten der Tagungsstätte erlauben nicht mehr als drei Parallelsitzungen, so daß nur 150 Beiträge zum mündlichen Vortrag kommen können, der Rest aber als Poster akzeptiert wird, deren Präsentation so attraktiv wie möglich organisiert werden soll. „We are expecting a strong German presence and scientific contribution" (S. Foster, 24. Januar 1997).

Weitere Rückfragen zu IAH-Themen an: Prof. Dr. E.P. Löhnert, IAH-Sektion Deutschland, Gustav-Freytag-Straße 75, 48161 Münster, Telefon 02533-2499, Telefax 02533-3443.

E.P. Löhnert, Münster

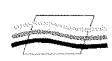

\section{Gesellschaft für UmweltGeowissen- schaften (GUG)}

\section{Geochemische Indikatoren in den Geo- und Umwelt- wissenschaften}

Mit dem Thema „Geochemische Indikatoren in den Geo- und Umweltwissenschaften" wenden sich die Deutsche Mineralogische Gesellschaft (Sektion Geochemie) und die GUG Gesellschaft für UmweltGeowissenschaften bewußt an die jüngeren Kolleginnen und Kollegen. Aber natürlich ist jede und jeder willkommen, an der Tagung junger Geochemiker teilzunehmen, die vom 08. bis 10. Mai 1997 am Institut für Mineralogie der Bergakademie Freiberg (das Mitveranstalter ist) stattfindet. Es können Vorträge (15 Min. plus Diskussionszeit) und Poster $\mathrm{zu}$ folgenden Themen eingereicht werden (je eher, umso besser):

- genetisch bedingte Signaturen, 